\title{
Ramification of gum arabic microencapsulation on the physicochemical and microbiological properties of butterfly pea (Clitoria ternatea) flowers using ultrasonic spray dryer
}

\author{
${ }^{1 *}$ Zainol, M.K., ${ }^{1}$ Lew, H.W., ${ }^{1}$ Mohd Zin, Z., ${ }^{1}$ Abd Razak, S.B., ${ }^{1}$ Mohd Maidin, N. and \\ ${ }^{2}$ Mamat, $\mathrm{H}$. \\ ${ }^{1}$ Faculty of Fisheries and Food Science, Universiti Malaysia Terengganu, 21030 Kuala Nerus, Terengganu, \\ Malaysia \\ ${ }^{2}$ Faculty of Food Science and Nutrition, Universiti Malaysia Sabah, 88400 Kota Kinabalu, Sabah, \\ Malaysia
}

\begin{abstract}
Article history:
Received: 7 November 2019

Received in revised form: 27

December 2019

Accepted: 29 December 2019

Available Online: 23 January 2020
\end{abstract}

\section{Keywords:}

Ultrasonic spray drying,

Microencapsulation,

Phenolic compounds,

Antioxidants,

Antimicrobial properties

DOI:

https://doi.org/10.26656/fr.2017.4(3).369

\begin{abstract}
Butterfly Pea (Clitoria ternatea) flower is commonly used to treat various diseases and has long been part of the science of phytomedicines. Ultrasonic assisted extraction technique is a simple, cheap and efficient alternative to traditional extraction methods, producing a much smaller particle size than conventional spray drier. This study was aimed to evaluate the physicochemical and microbiological properties of microencapsulated butterfly pea flower (MEBP) powder prepared using ultrasonic spraying technique. The samples were microencapsulated with different amount of Gum Arabic (GA) $(0,2,4,6,8$ and 10\%). Surface morphology of the MEBP powder was examined using SEM showed different molecular structures in different MEBP powder. FTIR analysis identified phenolic hydroxyl group $\left(1061.69 \mathrm{~cm}^{-1}\right.$ and $\left.3385.36 \mathrm{~cm}^{-1}\right)$, sulfite group (1062.01 $\mathrm{cm}^{-1}, 1065.92 \mathrm{~cm}^{-1}, 1077.15 \mathrm{~cm}^{-1}, 1234.72 \mathrm{~cm}^{-1}$ and $\left.1261.74 \mathrm{~cm}^{-1}\right)$ and amide group (1635.99 $\mathrm{cm}^{-1}, 1636.74 \mathrm{~cm}^{-1}, 1654.14 \mathrm{~cm}^{-1}$ and $\left.3417.2 \mathrm{~cm}^{-1}\right)$. 2,2-diphenyl-1 -picrylhydrazyl (DPPH), thiobarbituric acid (TBA), total phenolic content (TPC), total flavonoid content (TFC) found to be ranging from $35.85 \pm 0.57$ to $130.85 \pm 3.00 \mathrm{mg} \mathrm{GAE} / \mathrm{g}$ dried sample, $4.32 \pm 0.04$ to $6.90 \pm 0.11 \mathrm{mg}$ QE/g dried sample, respectively. It was found that Bacillus cereus was sensitive to MEBP powder as the results showed a prominent inhibition zone $(5.67 \pm 0.6 \mathrm{~mm}$ to $11.67 \pm 2.3 \mathrm{~mm})$. MEBP produced with GA $6 \%$ ultrasonic spray drier was found to be effective in sustaining its antioxidative activities and the microbial activities were found to be active. This result provided useful information data on the best technique to use ultrasonic spray dryer to retain antioxidant compounds.
\end{abstract}

\section{Introduction}

Butterfly Pea (Clitoria ternatea) flower is traditionally used to treat various ailments, have a vivid blue or white colour and are normally utilised as a natural food colorant in Southeast Asia due to its high stability in food (Sivarajan and Balachandran, 1994). Butterfly Pea has fuelled scientific advances in recent years that may have an impact on modern agriculture, biotechnology and medicine (Nguyen et al., 2014). Since time immemorial, these plant products have been part of phytomedicines that can be extracted from barks, leaves, bulbs, roots, fruits and seeds. Consumers are now interested in using natural pigments as opposed to artificial chemicals used in the food industry due to increased consumer health knowledge for a healthier diet (Montes et al., 2005), and the emphasis has been on identifying and researching natural pigments from natural sources, also known as antioxidants in plants (Zainol et al., 2003). Antioxidant compounds such as phenolic acids, polyphenols and flavonoids scavenge free radicals such as peroxide, hydroperoxide or lipid peroxyl and thus inhibit the mechanism of oxidation that leads to degenerative diseases (Prakash et al., 2012). A study conducted by Sushma and colleagues (Sushma et al., 2015) found the antioxidant properties in a Butterfly Pea extract facilitated the creation of nanoparticles of magnesium oxide, materials increasingly used for biomedical applications Exploring an alternative preservation (drying) method is needed to shorten proess time, decrease solvent consumption, increase extraction yield, and improve extract quality, as conventional solvent extraction methods require higher cost, longer 
time but low efficiency. Its stability and properties with different amounts of microencapsulating agents after treatment with ultrasonic drying could be useful to the study of antioxidant stability.

According to Xia et al. (2014), ultrasonic method is widely used in analytical procedures, particularly in sample preparation. Ultrasonic assisted extraction technique is a quick, cheap and effective alternative to conventional extraction methods. The big difference between traditional spray dryers is much smaller particle size using ultrasonic nozzle compared to the ultrasonic process. Ultrasonic spray drier sonic nozzle, with normal nozzles approximately $0.5 \mathrm{~mm}$ in size, can produce particles as small as 10 microns and smaller which could produce smaller particles and help to dry faster. The small particle sizes produced by ultrasonic nozzles make the best drying performance (Afoakwah et al., 2012). Due to the larger particle size for conventional nozzles, the large surface area does not allow efficient drying of particles. Another important aspect of using ultrasonic atomizer nozzle is because of the smaller size for lower heat energy or temperature. Consequently, the objective of this study was to calculate the physicochemical properties of microencapsulated butterfly pea powder (MEBP) such as antioxidant activity, total phenolic content and total flavonoid content as affected by ultrasonic spray drying based on the amount of GA as a microencapsulation agent. The findings of this research are essential to the development of a better product in order to maintain the beneficial properties of antioxidant compounds.

\section{Materials and methods}

\subsection{Raw materials and chemicals}

The butterfly pea flower used in this study was obtained from Kuala Nerus, Terengganu. The petals were separated from their calixes and stored at $-18^{\circ} \mathrm{C}$. Food grade Gum Arabic (GA) from purchased from Sudan (Elixir, Sudan).

\subsection{Sample preparation}

\subsubsection{Microencapsulation by ultrasonic spray drying}

The butterfly pea flower $(150 \mathrm{~g})$ was homogenized in $1500 \mathrm{~mL}$ distilled water, filtered with 2 plies of muslin cloth and microencapsulated with GA at $0,2,4,6,8$ and $10 \%$ concentration relative to solid content. Using an ultrasonic dryer, the emulsions were treated (YKNTECH, Kulim, Malaysia) equipped with a nozzle atomizer. The outlet temperature was set at $90^{\circ} \mathrm{C}$ and feed flow rate was kept at $8 \mathrm{~mL} \min ^{-1}$. The microencapsulated Butterfly Pea (MEBP) powder was collected and stored in opaque, heat sealed PP plastic at $4^{\circ} \mathrm{C}$ prior to further analysis.

\subsection{Moisture analysis of the MEBP powder}

Moisture content in MEBP powder was measured using the method approved by AOAC International (2007).

2.4 Antioxidant activities analysis using 2,2-diphenyl-2picrylydrazyl (DPPH) radical scavenging activity assay

Antioxidant activity of MEBP powder was determined by the 2, 2-diphenyl-2-picrylydrazyl (DPPH) method of Zainol et al. (2018) with some modifications. MEBP powder was adjusted to $6 \mathrm{mg} / \mathrm{mL}$ by dissolving $18 \mathrm{mg}$ sample in $3 \mathrm{~mL}$ methanol. An aliquot of $4.5 \mathrm{~mL}$ of $0.025 \%$ DPPH radical in methanol was added to a test tube with $3 \mathrm{~mL}$ sample, at $6 \mathrm{mg} / \mathrm{mL}$. The reaction mixture was mixed using vortex and let to stand at room temperature in the dark for 5 mins. The absorbance at $517 \mathrm{~nm}$ was measured every 15 to 60 mins.

\subsection{Antioxidant activities analysis using Thiobarbituric acid (TBA) test}

The test was conducted according to the method of Kikuzaki and Nakatani (1993). To $2.0 \mathrm{~mL}$ of the sample solution, $1.0 \mathrm{~mL}$ of $20 \%$ aqueous trichloroacetic acid (TCA) and $2.0 \mathrm{~mL}$ of $0.67 \%$ aqueous thiobarbituric acid (TBA) solution were added. The final sample concentration was $0.02 \% \mathrm{w} / \mathrm{v}$. The mixture was placed in a boiling water bath for 10 mins. After cooling to $25^{\circ}$ $\mathrm{C}$, it was then centrifuged at $3000 \mathrm{rpm}$ for 20 mins. The absorbance of the supernatant was measured at $531 \mathrm{~nm}$.

\subsection{Determination of total phenolic compound}

The total phenolic content of MEBP powder was evaluated using a method described by Kim et al. (2003). The sample with a concentration of $1 \mathrm{mg} / \mathrm{mL}$ methanol was added to $4.5 \mathrm{~mL}$ of deionized distilled water and 0.5 $\mathrm{mL}$ of Folin-Ciocalteu's reagent was then added to the solution. After mixing the tubes, they were maintained at room temperature for 5 mins followed by the addition of $5 \mathrm{~mL}$ of $7 \%$ sodium carbonate and $2 \mathrm{~mL}$ of deionized distilled water and incubated for 90 mins at $23^{\circ} \mathrm{C}$ with intermittent shaking, and measured at $750 \mathrm{~nm}$.

\subsection{Determination of total flavonoid content}

The flavonoid content of each MEBP powder was measured based on methods described by $\mathrm{Ng}$ et al. (2020). Briefly, $50 \mathrm{mg} / 10 \mathrm{~mL}$ methanol of sample was mixed with $1.5 \mathrm{~mL}$ of methanol and then, $0.1 \mathrm{~mL}$ of $10 \%$ aluminum chloride was added, followed by $0.1 \mathrm{~mL}$ of potassium acetate and $2.8 \mathrm{~mL}$ of distilled water. The mixtures were incubated at room temperature for 30 mins, and measured at $415 \mathrm{~nm}$. 
2.8 Antimicrobial effect of microencapsulated butterfly pea

The antimicrobial test was performed based on the method from Uma et al. (2009) with some modifications. The bacterial inoculums used in the test were Escherichia coli, Bacillus cereus, Staphylococcus auereus and Salmonella enterica serovar Typhi. The bacteria were prepared from overnight-grown cultures (24 hrs) in Nutrient Agar, and the turbidity was adjusted equivalent to $0.5 \mathrm{McF}$ arland units (approximately $1.2 \times$

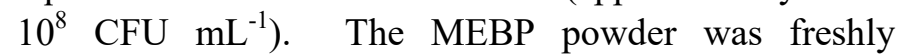
reconstituted with saline water at a concentration of 2 $\mathrm{mg} / \mathrm{mL}$. The wells on the agar were made using the end of the pipette tip and molten MHA agar was put into the well prior pipetting the sample into the wells. The plates were incubated at $37^{\circ} \mathrm{C}$ for $24 \mathrm{hrs}$. The diameters of zone of inhibition surrounding the wells were recorded.

\subsection{Surface morphology analysis}

The spray-dried MEBP powder was examined using a Hitachi TM1000 operating under vacuum (ca.10-7 mbar) at $1 \mathrm{kV}$ and $10 \mu \mathrm{A}$. The spray-dried MEBP powder was applied on the surface of sticker on a specimen holder. The sample was then coated with $99 \%$ pure gold using JFC 1600 Auto fine coater, before being analysed using Scanning electron microscope (SEM). The specimen was viewed using 90 times magnification to 250 times (Hau et al. 2018).

\subsection{Identification of functional groups}

The sampling technique used was transmission (4000-450 wavenumber), 64 scans modified from Durga Maha Lakshmi et al. (2014). The sample and KBr (FTIR grade) were made into pallet in the ratio of $10 \mathrm{mg}$ : $500 \mathrm{mg}$ using pallet maker.

\subsection{Statistical analysis}

All data were analyzed using one-way variance analysis (ANOVA) using SPSS (version 20) software. When $\mathrm{P}<0.05$, the values were considered significantly different. Mean comparisons were made using the LSD Fisher and the data was presented as a mean \pm standard deviation.

\section{Results and discussion}

\subsection{Moisture content}

Table 1 shows the moisture content of different GA levels of MEBP powder. Outlet air temperature and drying aid have helped to reduce the moisture content of MEBP powder to a lower level. The $8 \%$ GA ultrasonic spray has the lowest moisture content, while the $2 \%$ GA ultrasonic spray dryer of the aqueous extract sample has the highest moisture content. Amid et al. (2013) found that GA had the weakest water holding capacity among sodium alginate, kappa carrageenan, guar gum and pectin due to its high solubility and high concentration due to the presence of many hydroxyl groups and the nature of the molecular structure of its monosaccharides.

\subsection{Antioxidant activities using 2,2-diphenyl-2-} picrylydrazyl (DPPH) radical scavenging activity assay

Table 1 also shows that all MEBP powder samples were equally effective free radical inhibitors or scavengers, which react with free DPPH radicals and may limit free radical damage. This may be due to the incomplete dissolution of the sample in a solution that causes less antioxidant compounds to react with DPPH radicals. At the end of the incubation period, BHT and $\alpha$ -tocopherol showed $79.59 \%$ and $74.60 \%$ inhibition of DPPH, respectively. This evidence is consistent with the research carried out by Ghadermazi and co-workers who have saturated artificial antioxidants with better antioxidant properties than natural antioxidants (Ghadermazi et al., 2017). MEBP powder sample encapsulated with $8 \%$ GA exhibited the best radical scavenging activity among all those which, due to the good condition or non-clotting state of the microencapsulated powder, were able to fully demonstrate its antioxidant capacity.

Table 1. Moisture content and antioxidative activities of microencapsulated butterfly pea flower (MEBP)

\begin{tabular}{cccccc}
\hline $\begin{array}{c}\text { Sample (\% of Arabic } \\
\text { gum) }\end{array}$ & $\begin{array}{c}\text { Moisture content } \\
(\%)\end{array}$ & DPPH (\%) & TBA & $\begin{array}{c}\text { TPC (mg GAE/g dried } \\
\text { sample }\end{array}$ & $\begin{array}{c}\text { TFC (mg QE/g dried } \\
\text { sample) }\end{array}$ \\
\hline 2 & $5.53 \pm 0.94^{\mathrm{a}}$ & $49.53 \pm 8.94^{\mathrm{d}}$ & $12.50 \pm 2.10^{\mathrm{c}}$ & $38.09 \pm 2.73^{\mathrm{b}}$ & $4.60 \pm 0.23^{\mathrm{c}}$ \\
4 & $5.53 \pm 0.94^{\mathrm{a}}$ & $56.92 \pm 0.81^{\mathrm{c}}$ & $18.30 \pm 0.11^{\mathrm{c}}$ & $35.85 \pm 3.67^{\mathrm{c}}$ & $5.35 \pm 0.17^{\mathrm{b}}$ \\
6 & $4.32 \pm 0.72^{\mathrm{a}}$ & $67.32 \pm 5.55^{\mathrm{b}}$ & $23.30 \pm 1.40^{\mathrm{c}}$ & $30.85 \pm 3.25^{\mathrm{a}}$ & $6.90 \pm 0.34^{\mathrm{a}}$ \\
8 & $2.30 \pm 0.91^{\mathrm{b}}$ & $70.25 \pm 9.11^{\mathrm{b}}$ & $27.33 \pm 4.25^{\mathrm{b}}$ & $32.69 \pm 2.77^{\mathrm{a}}$ & $6.73 \pm 0.25^{\mathrm{a}}$ \\
10 & $2.40 \pm 0.51^{\mathrm{b}}$ & $60.25 \pm 9.11^{\mathrm{b}}$ & $21.33 \pm 6.65^{\mathrm{b}}$ & $35.65 \pm 2.57^{\mathrm{a}}$ & $5.93 \pm 0.65^{\mathrm{a}}$ \\
BHT & - & $79.59 \pm 3.80^{\mathrm{a}}$ & $25.15 \pm 2.05^{\mathrm{b}}$ & - & - \\
a-tocopherol & - & $74.60 \pm 5.50^{\mathrm{ab}}$ & $35.74 \pm 2.47^{\mathrm{a}}$ & - & - \\
\hline
\end{tabular}

All data was expressed as means of replicates \pm standard deviation. Mean with different superscript letters are significantly different at $\mathrm{p}<0.05$ within columns. 


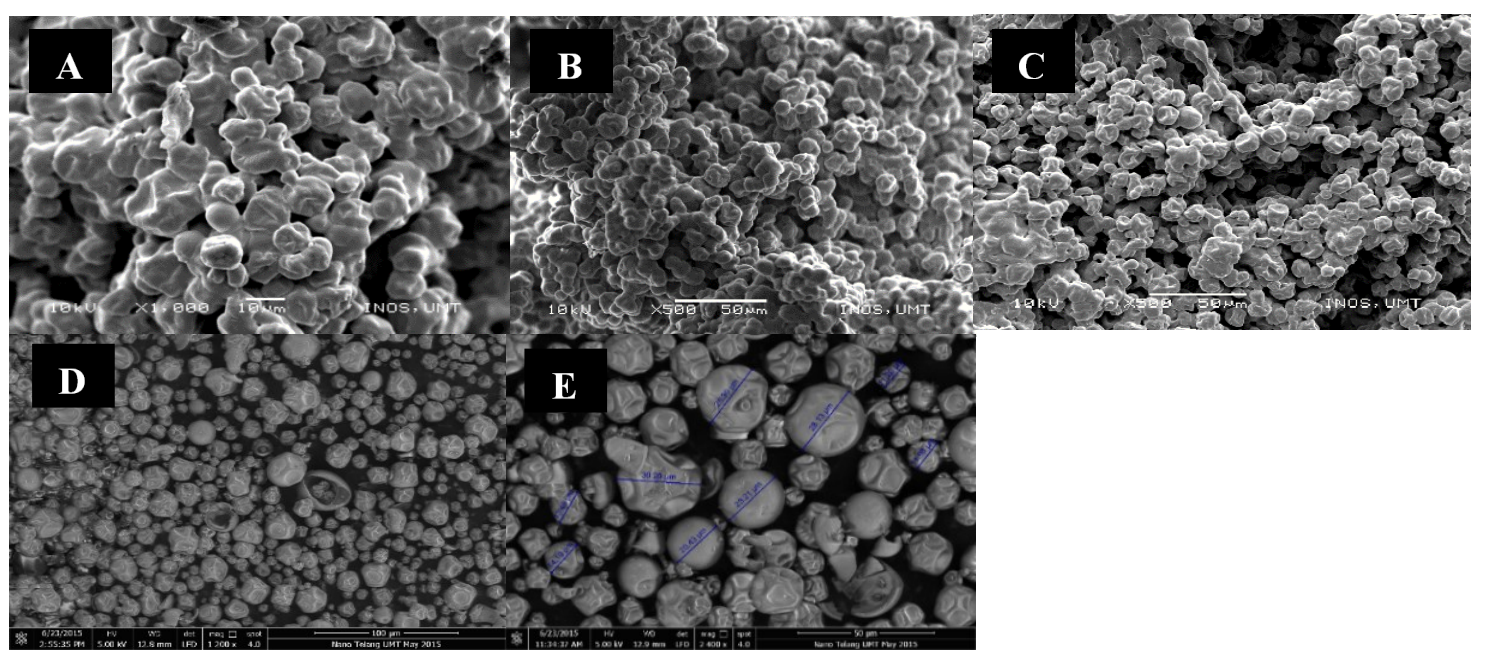

Figure 1. Differences between the surface of the microencapsulated particle in SEM image of MEBP powder encapsulated with $2,4,6,8$ and $10 \%$ GA. A $=2 \%$ GA; B: $4 \%$ GA ; $: 6 \%$ D: $8 \%$ and E: $10 \%$ GA.

\subsection{Antioxidant activities using Thiobarbituric acid known as hydrophilic antioxidants.}

(TBA) test

Table 1 shows the direct measurement of carbonyl formed during the secondary stage of lipid peroxidation through the TBA method found that sample coated with $8 \%$ GA showed the best antioxidative activities. This may be because when the sample possessed strong antioxidant properties, the chances to achieve high amount of malonaldehyde at the later stage of lipid peroxidation is lower as the initial stage of lipid peroxidation has been thwarted by the antioxidant compounds. In addition, the antioxidant activity detected with the TBA method was lower than that detected using DppH method. The present study contrasts with the results of previous findings on Prunella vulgaris by Rasool et al. (2010), where the antioxidant activity of TBA occurs. The amount of peroxide in the initial stage of lipid peroxidation may be suggested to be higher than in the secondary stage the amount of peroxide.

\subsection{Determination of total phenolic content}

Table 1 also reveals that all of the MEBP powder contained an appreciable amount of phenolic compounds. The 6\% GA encapsulated sample showed the highest TPC $(130.85 \pm 3.00 \mathrm{mg}$ GAE / g dried sample) indicating that the powder produced may have a potential role as an antioxidant-rich ingredient in food or nutraceutical formulations. This may be due to the role of GA as protective agents to reduce heat treatment degradation of polyphenolic compounds. Besides that, the high amount of total phenolic is explained by Rabeta and An Nabil (2013) who mentioned that phenolic compounds are water-soluble natural antioxidants which normally an aromatic ring bearing one or more hydroxyl substituent. In a study conducted by Sadeghi et al. (2015), a positive relationship between high antioxidant activity and phenolic content for different part of the plant was shown and this is why phenolic compounds are

\subsection{Determination of total flavonoid content}

Table 1 also reveals that there was a significant amount of total flavonoid content (TFC) in all MEBP material. The range of total flavonoid content obtained was between $4.32 \pm 0.04$ to $6.90 \pm 0.11 \mathrm{mg} \mathrm{QE} / \mathrm{g}$ dried sample. Higher TFC was found in MEBP coated with $6 \%$ GA $(\mathrm{p}<0.05)$ whereas lower TFC was found in MEBP coated with 4\% GA which displayed no significant $(p>0.05)$ different. Overall, extracts with a high activity of radical scavenging also showed high flavonoid content, but good correlations between TPC and TFC could not be found. Keshani et al. (2015) and Saeed et al. (2012) reported that only flavonoids with a certain structure and particularly hydroxyl position in the molecule can act as proton donating and show radical scavenging activity. There has not yet been identified the recommended daily intake of anthocyanins, one of the potent flavonoids. However, a specific proposed level of $50 \mathrm{mg}$ /day has currently been defined by China (Wallace and Giusti, 2015).

\subsection{Surface morphology analysis}

Figure 1 shows a distinct difference in SEM image of MEBP powder encapsulated with 2, 4, 6, 8 and 10\% GA between the layer of the microencapsulated material.The $2 \%$ samples gave a rougher and dented surfaces as compared to sample encapsulated with $6 \%$ which exhibited very good homogenous morphology: spherical shaped, smooth-surfaced particles that varied slightly in size and were free of visible cracks and pores. According to Izydorczyk et al. (2005), the result is that GA is a low viscosity gum and its solution exhibits Newtonian flow behavior even at high concentrations, so the microparticles at higher concentration will have better free-flow properties. The formation of these indentations on the surface of particles obtained by spray 
drying is usually attributed to particle shrinkage due to the drastic loss of moisture followed by cooling (Tonon, 2010). This study also showed that spray-dried microparticles were individual spheres and the results are in conformance with Santana et al. (2013) who encapsulate babassu coconut milk using spray dry technique as well.

\subsection{Identification of functional groups}

Table 2 depicts the MEBP powder complexity of infrared spectra in the FTIR spectroscopy 1450 to 600 $\mathrm{cm}^{-1}$ region which makes it difficult to assign all the absorption bands, and because of the unique patterns found there, it is often called the fingerprint region. The strong band observed at $1062.01 \mathrm{~cm}^{-1}, 1065.92 \mathrm{~cm}^{-1}$, $1077.15 \mathrm{~cm}^{-1}, 1234.72 \mathrm{~cm}^{-1}$ and $1261.74 \mathrm{~cm}^{-1}$ were attributed to sulfite group. The band at $1635.99 \mathrm{~cm}^{-1}$, $1636.74 \mathrm{~cm}^{-1}, 1654.14 \mathrm{~cm}^{-1}$ and $3417.2 \mathrm{~cm}^{-1}$ revealed the presence of $\mathrm{C}=\mathrm{N}$ stretching of amide groups (Figure 2). The peak at $1061.69 \mathrm{~cm}^{-1}$ and $3385.36 \mathrm{~cm}^{-1}$ confirmed the presence of alcohol and phenol groups. From IRspectrum, we can conclude that the MEBP extract from spray drying technique has aromatic structures contain phenolic hydroxyl groups, amide groups, and sulfite groups within its structure. The present results were in accordance to the analysis conducted by Maobe and Nyarango (2013) on Warburgia ugandensis which was extracted using hexane and dichloromethane, both the amides and alcohols functional group appeared at 1643.2 $\mathrm{cm}^{-1}$ and $3444.6 \mathrm{~cm}^{-1}$, respectively.

\subsection{Antimicrobial effect of MEBP powder}

The purpose of having GA as one of the experimental units was to confirm that the antibacterial activity solely comes from butterfly pea rather than from GA (Table 3). It is interesting to note that only B.cereus was the most susceptible microorganism in the investigation against MEBP powder. The larger the zone, the more sensitive the bacterium is to the plant extract. In this case, sample coated with $4 \%$ and $6 \%$ GA showed no significant different ( $p>0.05)$ with the zone of inhibition $11.67 \pm 2.3 \mathrm{~mm}$ and $11.33 \pm 0.6 \mathrm{~mm}$, respectively. This may be caused by the suffice effectiveness of the phytochemicals present in MEBP powder when compare to sample with only $2 \%$ GA at the same processing temperature. The intensity of the activity detected in the present study may simply due to the poor diffusion of flavonoids through the medium and the dissimilar volume of sample extract in the well due to the varied thickness of the agar. Gram-positive bacteria B.cereus was susceptible to the antibacterial activity of plant extracts, which supported the finding that plant extracts are usually more active against Gram-positive bacteria than Gram-negative (Palombo and Semple, 2001). According to Tortora et al. (2001), susceptibility differences between Gram-positive and Gram-negative bacteria may be due to cell wall structural differences between these classes of bacteria. It has been suggested in previous research that the type of solvents such as chloroform, methanol and petroleum ether used to extract Butterfly Pea blue flowers will possess different efficacy against tested microorganisms. Therefore, no zone of inhibition was observed for E. coli, S. enterica serovar Typhi and $S$. aureus may be due to the unsuitability of the solvent extraction in addition to the strong resistant towards the antibacterial compound. Similar results were obtained by Uma et al. (2009) who stated that Butterfly Pea flowers exhibit comparatively high activity as compared with chloroform and aqueous extracts.

\section{Conclusion}

At higher percentage of GA, the yield production of MEBP showed a gradual increment as well as significant increase in lightness value $\left(\mathrm{L}^{*}\right)$ and blue colour $\left(\mathrm{b}^{*}\right)$. The moisture content of MEBP was also lower at higher GA. Morphology of particles was found to be circular in shape at lower GA and rougher surface at higher GA. FTIR analysis revealed the detected functional groups in Butterfly Pea flower as phenolic hydroxyl groups, amide groups, and sulfite groups. TPC of MEBP was found to

\begin{tabular}{|c|c|c|c|c|}
\hline No & Peak Value $\left(\mathrm{cm}^{-1}\right)$ & Stretching & Interpretation & Reference \\
\hline 1 & 1061.69 & O-H stretching & Alcohol & Present study \\
\hline 2 & 1062.01 & $\mathrm{~S}=\mathrm{O}$ stretching & Sulfite & Present study \\
\hline 3 & 1065.92 & $\mathrm{~S}=\mathrm{O}$ stretching & Sulfite & Present study \\
\hline 4 & 1077.15 & $\mathrm{~S}=\mathrm{O}$ stretching & Sulfite & Present study \\
\hline 5 & 1234.72 & $\mathrm{~S}=\mathrm{O}$ stretching & Sulfite & Present study \\
\hline 6 & 1261.74 & $\mathrm{~S}=\mathrm{O}$ stretching & Sulfite & Present study \\
\hline 7 & 1635.99 & $\mathrm{C}=\mathrm{N}$ stretching & Amide & Present study \\
\hline 8 & 1636.74 & $\mathrm{C}=\mathrm{N}$ stretching & Amide & Maobe and Nyarango (2013) \\
\hline 9 & 1654.14 & $\mathrm{C}=\mathrm{N}$ stretching & Amide & Present study \\
\hline 10 & 3385.36 & O-H stretching & Alcohol & Durga Maha Lakshmi et al. (2015) \\
\hline 11 & 3417.2 & $\mathrm{C}=\mathrm{N}$ stretching & Amide & Packialakshmi (2014) \\
\hline 12 & 3444.06 & O-H stretching & Alcohol & Maobe and Nyarango (2013) \\
\hline
\end{tabular}




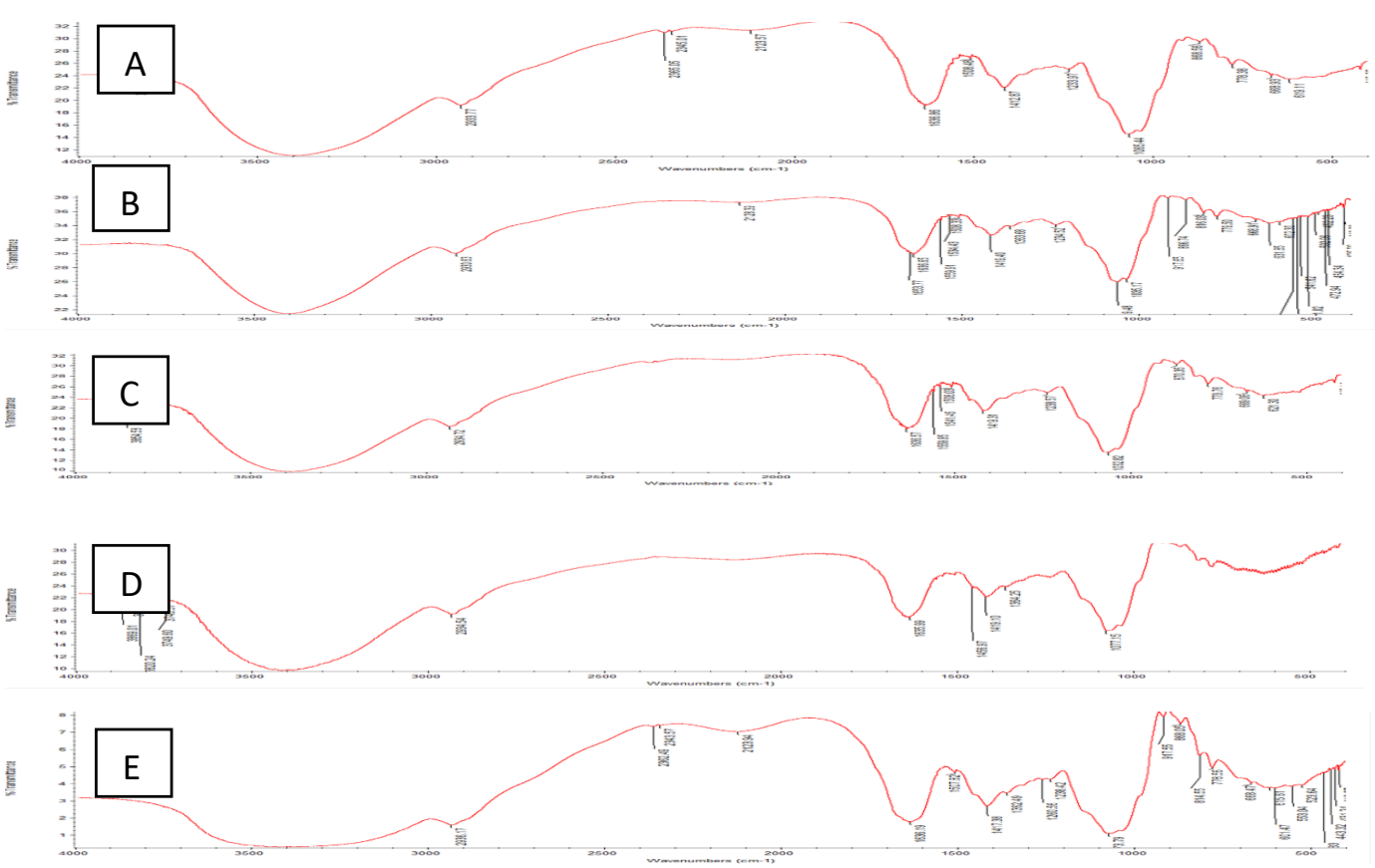

Figure 2. MEBP spectrum analysed in FTIR

Table 3. Antimicrobial activity of C. ternatea Linn flower extracts by well diffusion

\begin{tabular}{lcccc}
\hline \multirow{2}{*}{ Sample } & \multicolumn{4}{c}{ Mean diameter of inhibition zone (mm) } \\
\cline { 2 - 5 } & Escherichia coli & S. enterica serovar Typhi & Bacillus cereus & Staphylococcus aureus \\
\hline GA & - & - & 0 & - \\
$2 \% \mathrm{GA}$ & - & - & $5.7 \pm 0.6^{\mathrm{b}}$ & - \\
$4 \% \mathrm{GA}$ & - & - & $6.0 \pm 1.0^{\mathrm{b}}$ & - \\
$6 \% \mathrm{GA}$ & - & - & $6.7 \pm 0.3^{\mathrm{b}}$ & - \\
$8 \% \mathrm{GA}$ & - & - & $7.7 \pm 0.4^{\mathrm{a}}$ & - \\
$10 \% \mathrm{GA}$ & - & - & $7.8 \pm 0.6^{\mathrm{a}}$ & - \\
\hline
\end{tabular}

Data are expressed as mean \pm SD of triplicate experiments. Mean value with different letters are significantly different at $\mathrm{p}<0.05$.

be in the range of $35.85 \pm 0.57$ to $130.85 \pm 3.00 \mathrm{mg} \mathrm{GAE} /$ g. As for TFC, the values were lower which $4.32 \pm 0.04$ to $6.90 \pm 0.11 \mathrm{mg}$ QE/g. MEBP powder treated with $6 \%$ GA possessed the best antioxidative activities in DPPH radical scavenging assay and TBA method. MEBP also demonstrated a good antibacterial activity against $B$. cereus by showing a wide clear zone of inhibition $(7.8 \pm 0.6 \mathrm{~mm}$ to $11.67 \pm 2.3 \mathrm{~mm})$. This work suggested that the use of GA as the microencapsulating agent can preserve antioxidant and antibacterial properties of Butterfly Pea flower.

\section{Conflict of Interest}

The authors declare no conflict of interest

\section{Acknowledgement}

This research was supported by a grant (NRGS/53131) from the research council of Universiti Malaysia Terengganu. The authors also wish to thank the Faculty of Fisheries and Food Sciences, Universiti Malaysia Terengganu for the laboratory and equipment provided.

\section{References}

Afoakwah, A., Adomako, C.N., Owusu, J., Engman, N. and Hannah, A.A. (2012). Spray Drying as an Appropriate Technology for the Food and Pharmaceutical Industries - A Review. Journal of Environmental Science, Computer Science and Engineering and Technology, 1(3), 467-476.

Amid, B.T., Mirhosseini, H. Poorazarang, H. and Mortazavi, S.A. (2013). Implications of partial conjugation of whey protein isolate to durian seed gum through Maillard reactions: foaming properties, water holding capacity and interfacial activity. Molecules, 18(12), 15110-15125. https:// doi.org/10.3390/molecules181215110.

AOAC International. (2007). Official Methods of Analysis

AOAC International. AOAC Official Method 990.26. $17^{\text {th }}$ ed. Gaithersburg, MD. USA: AOAC International,

Durga Maha Lakshmi, C.H.N., Deva Prasad Raju, B., Madhavi, T. and John Sushma, N. (2014). Identification of bioactive compounds by FTIR 
analysis and in vitro antioxidant activity of Clitoria ternatea leaf and flower extracts. Indo American Journal of Pharmaceutical Research, 4(9), 38943903.

Ghadermazi, R., Keramat, J. and Goli, S.A.H. (2017) Antioxidant activity of clove (Eugenia caryophyllata Thunb), oregano (Oringanum vulgare L) and sage (Salvia officinalis L) essential oils in various model systems. International Food Research Journal, 24 (4), 1628-1635.

Hau, E.H., Mohd Zin, Z., Nasution, Z., Shaharudin, N.A. and Zainol, M.K. (2018). Physicochemical properties of powdered protein hydrolysate from Yellowstripe scad (Selaroides leptolepis) fish. International Food Research Journal, 25(6), 2555-2561.

Keshani, S., Wan Daud, W.R., Nourouzi, M.M., Namvar, F. and Ghasemi, M. (2015). Spray drying: An overview on wall deposition, process and modeling. Journal of Food Engineering, 146, 152162. https://doi.org/10.1016/j.jfoodeng.2014.09.004.

Kikuzaki, H. and Nakatani, N. (1993). Antioxidant effects of some ginger constituents. Journal of Food Sciences, 58(6), 1407-1410. https://doi.org/10.1111/ j.1365-2621.1993.tb06194.x.

Kim, D.O., Jeong, S.W. and Lee, C.Y. (2003). Antioxidant capacity of phenolic phytochemicals from various cultivars of plums. Food Chemistry, 81 (3), 321-326. https://doi.org/10.1016/S0308-8146 (02)00423-5.

Maobe, M.A.G. and Nyarango, R.M. (2013). Fourier transformer infra-red spectrophotometer analysis of Warburgia ugandensis medicinal herb used for the treatment of diabetes, malaria and pneumonia in kisii region, southwest kenya. Global Journal of Pharmacology, 7(1), 61-68. https://doi.org/10.5829/ idosi.gjp.2013.7.1.7226

Montes, C., Vica'rio, I.M., Raymundo, M., Fett, R. and Heredia, F.J. (2005). Application of tristimulus colorimetry to optimize the extraction of anthocyanins from Jaboticaba (Myricia jaboticaba Berg.). Food Research International, 38(8-9), 983988. https://doi.org/10.1016/j.foodres.2005.01.016

Nguyen, G.K., Wang, S., Qiu, Y., Hemu, X., Lian, Y. and Tam, J.P. (2014). Butelase 1 is an Asx-specific ligase enabling peptide macrocyclization and synthesis. Nature Chemical Biology, 10, 732-738. https://doi.org/10.1038/nchembio.1586

Ng, K.S., Mohd Zin, Z., Mohd Maidin, N., Abdullah, M.A.A. and Zainol, M.K. (2020) Effect of steaming time on antioxidant properties of Napier grass herbal tea by green tea processing method. Food Research, 4(1), 175 - 183. https://doi.org/10.26656/fr.2017.4
(1).263

Palombo, E.A. and Semple, S.J. (2001). Antibacterial activity of traditional Australian medicinal plants. Journal of Ethnopharmacology, 77(2-3), 151-157. https://doi.org/10.1016/s0378-8741(01)00290-2

Prakash, D., Upadhyay, G., Gupta, C., Pushpangadan, P. and Singh, K.K. (2012). Antioxidant and free radical scavenging activities of some promising wild edible fruits. International Food Research Journal, 19(3), 1109-1116.

Rabeta, M.S. and An Nabil, Z. (2013). Total phenolic compounds and scavenging activity in Clitoria ternatea and Vitex negundo linn. International Food Research Journal, 20(1), 495-500.

Rasool, R., Ahmad Ganai, B., Kamili, A.N., Akbar, S. and Masood, A. (2010). Antioxidant and antibacterial activities of extracts from wild and in vitro-raised cultures of Prunella vulgaris L. Medicinal and Aromatic Plant Science and Biotechnology, 4(1), 20-27.

Saeed, N., Khan, M.R. and Shabbir, M. (2012). Antioxidant activity, total phenolic and total flavonoids contents of whole plant extracts Torilis leptophylla L. BMC Complementary and Alternative Medicine, 12, 221-233. https://doi.org/10.1186/14726882-12-221

Santana, A.A., de Oliveira, R.A., Pinedo, A.A., Kurozawa, L.E. and Park, K.J. (2013). Microencapsulation of babassu coconut milk. Food Science and Technology (Campinas), 33(4), 737744 . $\quad$ https://doi.org/10.1590/s010120612013000400020

Sivarajan, V.V. and Balachandran, I. (1994). Ayurvedic drug and their plant sources. Oxford and IBH, 425428.

Tonon, R.V., Brabet, C. and Rubinger, M.D. (2010). Anthocyanin stability and antioxidant activity of spray-dried açai (Euterpe oleracea Mart.) juice produced with different carrier agents. Food Research International, 43(3), 907-914. https:// doi.org/10.1016/j.foodres.2009.12.013

Tortora, G.J., Funke, B.R. and Case, C.L. (2001). Microbiology: An Introduction. $12^{\text {th }}$ ed. San Francisco: Benjamin Cummings.

Uma, B., Prabhakar, K. and Rajendran, S. (2009). Phytochemical analysis and antimicrobial activity of Clitoria ternatea Linn against extended spectrum beta-lactamase producing enteric and urinary pathogens. Asian Journal of Pharmaceutical and Clinical Research, 2(4), 94-96.

Wallace, T.C. and Giusti, M.M. (2015). Anthocyanins. Advances in Nutrition, 6(5), 620-622. https:// 
doi.org/10.3945/an.115.009233

Xia, Y.G., Yang, B.Y., Liang, J., Wang, D., Yang, Q. and Kuang, H.X. (2014). Optimization of simultaneous ultrasonic-assisted extraction of watersoluble and fat-soluble characteristic constituents from Forsythiae fructus using response surface methodology and high-performance liquid chromatography. Pharmacognosy Magazine, 10(39), 292-303. https://doi.org/10.4103/0973-1296.137370.

Zainol, M.K., Wong, K.Y., Mohd Zin, Z., Kamarudin, K.S., Danish-Daniel, A., Ng. K.S. and Mamat, H. (2018). Effect of ethanol in ultrasonic assisted extraction technique on antioxidative properties of passion fruit (Passiflora edulis) leaves. Malaysian Applied Biology Journal, 47(6), 19-27.

Zainol, M.K., Abdul-Hamid, A., Yusof, S. and Muse, R. (2003). Antioxidative activity and total phenolic compounds of leaf root and petiole of four accessions of Centella asiatica. Food Chemistry, 81 (4), 575-581. https://doi.org/10.1016/S0308-8146 (02)00498-3 